\title{
THE FORMATION OF PROFESSIONAL COMPETENCE BY MEANS OF ECONOMIC DISCIPLINES
}

\author{
Rifat Rifovich Fakhrutdinov \\ Kazan Federal University \\ Rezida Akhatovna Fahrutdinova \\ Kazan Federal University
}

\begin{abstract}
Economy, rapidly developing in recent years, is a powerful tool of research of professional competences of students in sphere of the economic subjects. The knowledge of economy has opened up opportunities for these areas of life, as Bank lending, currency, currency market, competition in the market, business and entrepreneurship. Since the inception of the traditional knowledge educational paradigm took several centuries. The world has changed, but the educational system remains in its basic essence the same as in the beginning of its formation, and no longer meets the challenges of time. This manifests in particular in fact, that postindustrial or the new information society of the XXI century faces the problem of lack of sufficient number of personnel capable of immediately after College or University competent to work in new conditions. The situation, when a specialist with a diploma has a finite amount of knowledge in the absence of skills to use and refill, it becomes a limiting factor in the development of the productive forces of society. The article presents theoretical substantiation of the problem and practice - oriented material of experimental work on realization of model of formation of professional competences of students by means of economic disciplines.
\end{abstract}

Keywords: competence approach, professional competence, content of education, economic disciplines, professional training, and students.

\section{INTRODUCTION}

The economy of the future should be based not on information equated with knowledge but on the persons possessing knowledge on the advantages, abilities and qualities of the people, absorbed the achievements and the historical experience of world and national culture.

Different authors proposed many classifications of specific professional competences in the areas of specialists training. Analysis of pedagogical literature on the problem of professional competence, the history of the development of this concept shows all the ambiguity, polystructural character, the complexity of the concepts "competence", "competence", the complexity of their interpretation and the ideas of competence approach in education - General and professional.[1,2]

Let's regard possible course of decomposition of educational results within a dynamic technology of design of professional competences and competences of graduates.

The first step. There is a preliminary definition of professional functions. There are some rules of definition of professional functions:

1.The rule of mutual convenience: dedicated professional functions should reflect not only the objective structure of professional activities, but also the mutual convenience of the educational sector and the employer.

2. The rule of sertificationment: every professional function, with appropriate educational conditions, can be mastered separately to obtain the relevant certificate.[3]

The second step. On the basis of selected professional functions private elements - competence are defined. 
The methods of activity, which are set in the base of allocation of professional competences should be relatively independent and complete in fulfilling specific professional functions. [4]

The third step. On the basis of selected and agreed set of competencies local didactic units of knowledge and skills are determined.

The research process revealed contradictions between:

- the social necessity in the formation of economic competence of students of secondary professional education and the unwillingness of educational institutions to implement it;

- the objective necessity of optimization of process of formation of professional competence of students of secondary vocational education on the basis of creative integrated economic courses and insufficient development of its conceptual, methodological and software and methodological support;

-available practical experience of formation of economic competence of students of secondary professional education and its lack of understanding as systemic and holistic phenomenon of management.

According to the identified contradictions, the choice of theme of the research was made: "the management of the formation of professional competence of students by means of economic disciplines in the College environment". The research problem is: what are the pedagogical conditions of formation professional competences of students of secondary education by means of economic disciplines?

Object of research is: the process and result of formation of professional competences of students of secondary professional education.

Subject of research is: the pedagogical conditions providing formation of professional competences of students of secondary education by means of economic subjects.

The aim of our research is to explain theoretically and prove experimentally the efficiency of formation of professional competencies of College students by means of economic subjects.

The hypothesis of the research as follows: formation of professional competences of students of secondary vocational education by means of subjects of the economic cycle will be more effective if:

- the content of notion "professional competence of the student in the study of the subjects of the economic cycle" will be concretized on the basis of theoretical analysis;

- model of formation of professional competencies of students of secondary vocational education by means of economic subjects will be designed and implemented;

- the content of the educational programs of economic disciplines in the aspect of forming of professional competences of students of the College will be developed;

- the criteria, indicators of level of formation of professional competences of students of secondary education in the process of studying economic disciplines are the identified.

The research questions are:

1. To give theoretical-methodological explanation and determine the specificity of the process of formation of professional competences of students of secondary education by means of subjects of the economic cycle.

2. To develop, to explain theoretically and prove experimentally a model of formation of professional competence of students of secondary education by means of subjects of the economic cycle.

3. To identify the pedagogical conditions of formation professional competences of students of secondary education by means of subjects of the economic cycle and to prove experimentally their effectiveness. 


\section{RESEARCH METHODS}

Theme, hypothesis and research questions led to the choice of research methods,which are interrelated and complementary each other; theoretical (the study of the philosophical, pedagogical, psychological, sociological, methodological literature, scientific periodicals, design, modeling, synthesis of experience of activity of educational institutions); diagnostic (test); observation (teaching observation, diagnosis); experimental (summative, formative, and control stages of experiment); proximations (study of documentation, plans, programs and performance of students); statistical (quantitative and qualitative processing of materials using mathematical statistics). We have been selected and implemented a variety of techniques to identify the level of formation of professional competences of undergraduate students enrolled in field of study 080114 "Economics and accounting (by industry), namely: "Methods for diagnostics of educational motivation of students" (A. A. Rean and..Yakunin, modification of N. TS. Badmaeva); "Test: Willingness to work with information and information sources"; "a Comprehensive methodology to identify the level of formation of professional competence of students-economists".

\section{Theoretical - methodological basis of the research}

-activity theory (V. V. Davydov. A. N. Leontiev, R. H. Shakurov);

- the theory of pedagogical design (V. P. Bespalko, V. S. Lednev, M. I. Makhmutov, V. A. Slastenin);

-the concept of continuous professional education of the individual as a condition of its fulfillment and professionalization (B. S. Gershunsky. E. M. Ibragimova, G. V. mukhametzyanova, A. M. Novikov, etc.);

The formation of professional competence of students-economists carried out by means of professional disciplines of economic orientation, are included in curricula in areas of training 080114 "Economics and accounting (by industry). In the cycle of professional training includes subjects such as General professional direction "Economics organizations", "Statistics", "Finance, monetary circulation and credit", "accounting", "Analysis of financial and economic activities", "Business planning", "Fundamentals of marketing", "Taxes and taxation", "Management". The training also provided students continuous teaching practice, writing a research work (essay, coursework, graduation thesis), involvement in educational work in academic groups. In our view, the potential of professional disciplines of economic orientation in the training of studentseconomists able fully to form intellectually and economically-developed personality of the specialist of the new type.

The contents of these disciplines contributes to the formation of professional and personal qualities of future economists, which includes the following components: communication (information and guidance, motivation and incentive, control and corrective components); educational; educative; Gnostic; cognitive; structural planning; organizational; ethical; social; behavioral; philosophical etc.

An important component of model of formation professional competences of students is the selection of technologies, forms and methods of training.

The choice of a particular form of training and education depended on the specific pedagogical situations. The work with students proceeded in the form of classroom and extracurricular educational activities, independent work.

For effective learning process in the framework of teaching of professional disciplines of economic orientation requires the use of various traditional and innovative educational technologies. In the classroom we have been actively used such technologies as: problem-based learning; cooperative learning; contextual learning; interactive learning; brainstorming method. [5]

The use of certain methods should built with taking into account both the specifics of future profession of students-economists, and depending on the purpose and content of training.

Our developing model is an integrated, developing system, promoting formation of professional competence of students-economists in the educational space of the University. [6] 
We used the adapted technique, developed on the basis of a questionnaire of A. A. Rean and V. A. Yakunin to determine the level of formation of educational motivation of students. We also used techniques that characterize the explanation of the doctrine, selected V. G. Leontiev and N. TS.Badmaeva, which are presented in table 1.[7]

To diagnose the level of formation of educational motivation of students, we used the adapted technique, developed on the basis of a questionnaire of A. A. Rean and V. A. Yakunin. Was also used techniques that characterize the explanation of the doctrine, selected V. G. Leontiev and N. TS.Badmaeva, which are presented in table 1.[7]

The Fig. 2 shows the percentage of students ' responses according to the level of communicative motives. Among 205 respondents $64 \%$ rated their level as high, putting themselves at the highest score.

The level of formation of educational motivation of students( \%.)

\begin{tabular}{|l|l|l|l|l|l|l|}
\hline The levels & 1 & 2 & 3 & 4 & 5 \\
\hline The professional motivation & 0 & 4 & 8 & 18 & 70 \\
\hline The motivation of creative self-expression & 0 & 1 & 44 & 14 & 41 \\
\hline The educational activities motivation & 3 & 2 & 12 & 13 & 70 \\
\hline
\end{tabular}

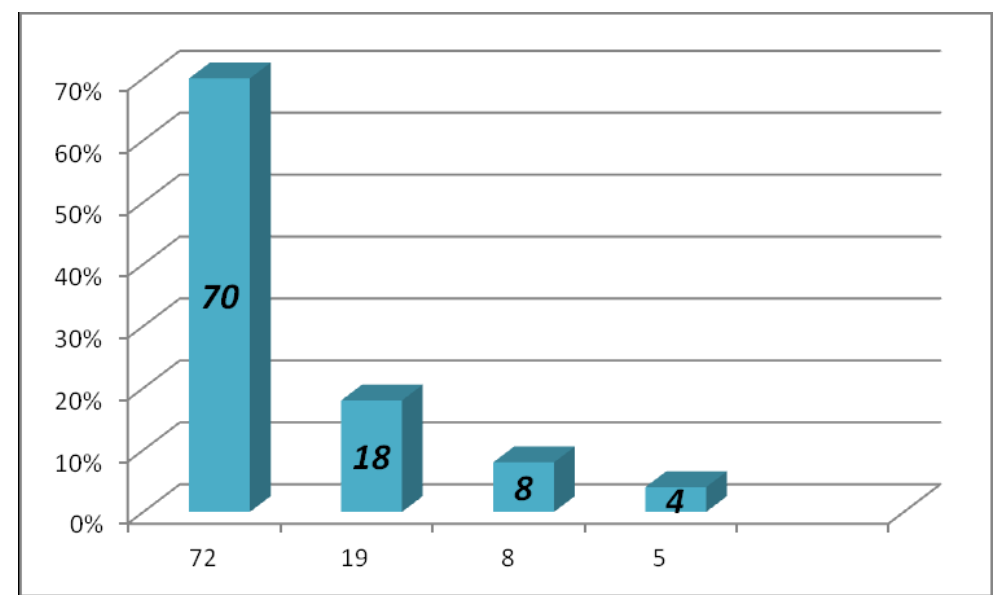

Fig.1 The level of formation of professional motivation of students( \%.)

Taking into account the obtained results in Fig.1 shows the percentage of students ' responses on the levels of completeness of their professional reasons. 

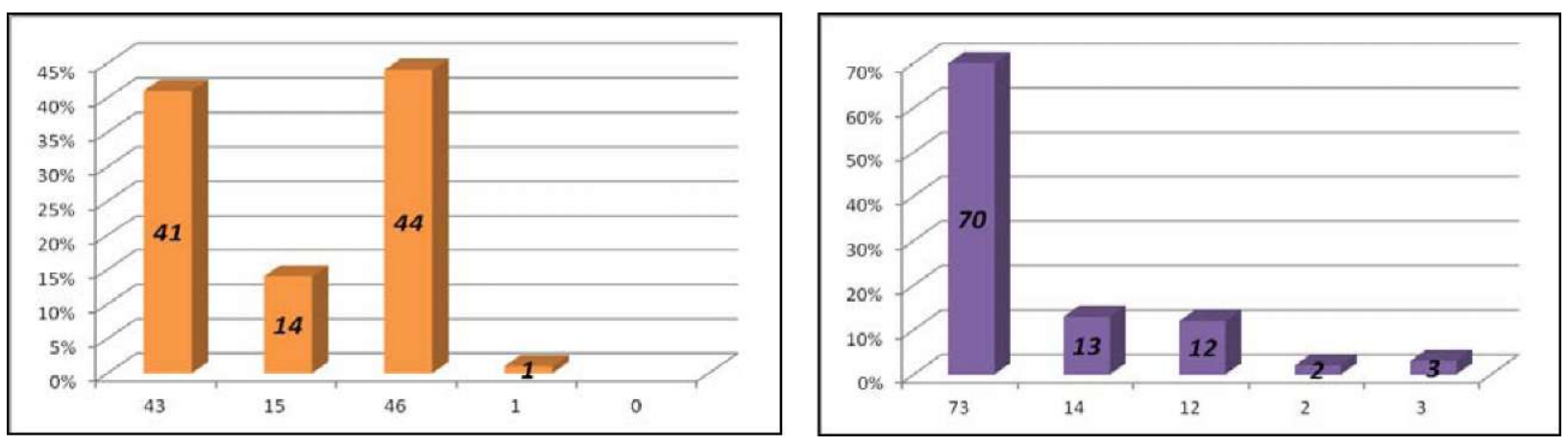

Fig.2. The level of formation of creative self-expression motivation of students( $\%$.)

Fig.3. The level of formation of educational activities motivation of students( $\%$.)

The Fig. 2 shows that the respondents ' answers were divided. 41\% said that the level of their motivation of creative self-expression is at a high level, and 44\% considered that they could assess yourself 3 points.

The Fig.3 shows that majority of students (70\%) assessed their the level of development of motives of educational activities of the highest grade. Almost equal percentages of students $(13 \%$ and $12 \%)$ rated themselves 4 and 3 points, and a small number of respondents felt that their educational-cognitive motives formed at a low level.

On the forming stage of the experiment we have implemented the model of formation of professional competence of future economists, but also pedagogical conditions, providing positive dynamics for the selected criteria. The results confirmed the validity of the hypotheses of the study.

\section{RESULTS}

The original contribution of the research is:

1. Clarified and elaborated the content of notion "professional competence of students of secondary education by means of subjects of the economic cycle, which is understood as an integral characteristic of personality, manifested in the General ability and readiness for professional activities in the economic environment, based on the totality of objective economic knowledge, which provides students with selfrealization and economic worldview that includes the existence of economic knowledge and economic actions (actions and skills of the student, aimed at independent mastering of economic knowledge, the economic judgment (evaluation, attitude) and economic needs (motives, interests), which manifests itself in economic competence.

2. The model of formation professional competences of students of secondary education by means of subjects of the economic cycle is developed. It contains interrelated components: methodological (aims, objectives, approaches, principles, functions, pedagogical conditions); substantial (an implementation of the author's course in Accounting, built upon an integrative-modular technology), activity (methods and tools), an efficiency criterion (performance - personal, cognitive, communicative, regulative universal educational actions, the main component of which in the context of our model are economic UUD, the criteria for their evaluation - economic knowledge and skills, levels of formation of professional competence is inadequate, basic, enhanced, outcome - student of secondary vocational education with basic or high level of formation of professional competence);

3.The pedagogical potential of educational institutions in formation of professional competence of students by means of subjects of economic disciplines is identified: the ability of increasing of student motivation through freedom of choice of forms of education, meet the economic and educational needs, creation of situations of success in economic activities for each student.

4. The criteria of research are developed. It includes as indicators of the level of formation of professional competences cognitive, personal, communicative and regulatory universal educational action (UUD); 
5. The pedagogical conditions promoting successful implementation of the proposed model, ensuring the adequacy of the aims, content, methods, and results of formation of professional competence of students by means of subjects of the economic cycle are identified and explained

Theoretical significance of the research is:

- identifying of specificity of the process of formation of professional competence of students of secondary education by means of subjects of economic disciplines;

- theoretical explanation of the aim, content, forms and methods, necessary and sufficient for the successful formation of professional competences of students of secondary education by means of subjects of the economic cycle;

- explanation of methodological approaches of formation of professional competence of students of secondary education by means of subjects of the economic cycle (active, cultural, individually-creative competence).

- determination of criterion characteristics of the efficiency of formation of professional competence of students of secondary education by means of subjects of the economic cycle.

\section{SUMMARY}

The practical significance of the research is

- the course "Accounting" is designed by research and practice of secondary educational institutions contributes to the successful formation of professional competences of students of secondary professional education;

- theoretical principles and foundations brought to the concrete methodical recommendations, implementation of which significantly increases the quality of teachers working in a professional;

- diagnostic tools, developing in accordance with the requirements of Federal educational standarts , contributes to the quality of measurement of efficiency of process of formation of professional competence of students of secondary education by means of disciplines of economic cycle;

- the results of dissertation research can be used to conduct a comprehensive research towards further improvement of the process of formation of professional competence of students by means of economic subjects;

- conclusions, foundations and empirical material, questionnaires, tests and methods can be used in schools, institutes of improvement of professional skill and retraining of education workers.

\section{CONCLUSION}

The article presents theoretical substantiation of the problem and practice - oriented material of experimental work on realization of model of formation of professional competences of students by means of economic disciplines.

\section{ACKNOWLEDGEMENT}

The research is performed according to the Russian Government Program of Competitive Growth of Kazan Federal University.

\section{REFERENCES}

Zimnyaya, I.A. Innovation competence programme for the academic discipline: design experience./ Under the scientific.ed. Doc.crazy.Sciences, Prof., Acad. AND RW..Winter. Research center of problems of quality of preparation of experts of 2008.

Zeer E, Cimanuk E. Competence approach to modernization of professional education. Higher education in Russia, 2005, No. 4. With 23-30.Kharisov F. F., Kharisova Ch. M. Life Science Journal 2014;11(11s) 
Rezida A. Fakhurtdinova, Ekaterina A. Konopatskaya. Formation of Common Competences in the StudentsFuture Teachers of Foreign Languages During the Process of Professional Training at University /The Social Sciences-Medwell Journals, 2015, 10(7), p.1768-1772.

Rezida A. Fahrutdinova, Rifat R. Fahrutdinov, Rinat N. Yusupov. The Model of Forming Communicative Competence of Students in the Process of Teaching the English Language / International Journal of Environmental \& Science Education- 2015, - №10(6), - c. 921-939

Konopatskaya E. A., Abdrafikov A. R., Armati I. E. Professional evolution of student's personality in conditions of poly-cultural educational space of the university / A. R. Abdurafikov, E. A. konopacka, I. e Armacies//Social Sciences (Pakistan). - 2015. - Vol. 10 - No. 5. - P. 556-561

The method for diagnostics of educational motivation of students (A. A. Rean, V. A. Yakunin, modification of N. Badmaeva TS) / N. C. Badmaeva // Influence of motivational factors on the development of mental abilities]. - Ulan-Ude, 2004. - P. 151-154. 